Send your letters to the editor, British Dental Journal, 64 Wimpole Street, London W1G 8YS E-mailbdj@bda.org

Priority will be given to letters less than 500 words long. Authors must sign the letter, which may be edited for reasons of space.

\section{Illogical guidance}

Sir, your editorial and the opinion piece by David Croser (BDJ 2006; 201: 485, 497-499) highlight the completely illogical guidance of the Department of Health and United Kingdom Advisory Panel on Blood Borne Viruses (UKAP) on HIV positive dentists. Although UKAP only issues 'guidance', in practice its advice is mandatory and clinicians involved with HIV positive dentists would always follow it. Although each individual HIV positive dentist is considered separately, this seems again to be excessive and not a reflection of the science and knowledge available.

As an expert who has advised in cases of HIV positive dentists, the guidance given by UKAP does not have a risk assessment which is safe legally and is completely open to challenge. The 'look back' exercises are costly both in monetary terms and psychological distress for patients. They also render the practice of HIV positive dentists almost financially worthless, if it is deemed that this is the end of his or her professional career. It is difficult to see how 'look backs' achieve anything apart from assuaging supervising clinicians that they are doing something active and ensuring that they are adhering to the UKAP guidelines. It is noteworthy that the necessity for 'look backs' has been successfully legally challenged and found to be unnecessary. The next legal step is for an HIV positive dentist to challenge the UKAP advice about cessation of practice. I sincerely hope that this will not be needed and UKAP will urgently reconsider their advice to dentists, after all they are clinical scientists and they can read the literature and evaluate risk, can't they?

M. V. Martin

Somerset

doi: 10.1038/sj.bdj.4814312

\section{Unacceptable treatment}

Sir, may I congratulate you for the strong leadership you have shown in highlighting the unacceptable way in which infected dental healthcare workers are treated in this country. David Croser, who as you may know is a colleague of mine here at Dental Protection, has provided your readers with a concise and balanced summary of the present position (Written off. BDJ 2006; 201: 497-499). What David did not say is that his own perspective is enriched by having devoted much of his recent career to treating and supporting HIV positive patients.

In the same way, Dental Protection has its own special perspective to bring to the debate. We have assisted many members in the UK and internationally who were infected with HIV and other blood-borne viruses. Many of our members work in countries where the incidence of such infections is exceptionally high, often acquired through vertical transmission.

The high profile legal challenges we mounted here in the UK in the cases of $\mathrm{H}$ (A Healthcare Worker) vs. Associated Newspapers Limited, and H (A Healthcare Worker) vs. N (A Health Authority) fought two important points of principle. Firstly, regarding a dentist's right to confidentiality and secondly, the need to adopt a proportional, evidence-based approach to look back exercises, instead of running around like headless chickens in order to satisfy irrational public perceptions and mediastoked fears.

My Dental Protection colleagues and I see at first hand the damage unnecessarily caused at a professional, personal and human level by the double standards currently applied. You cannot require healthcare professionals to act ethically in their approach to patients with bloodborne infections, and to respect the evidence base, when the same courtesy is not consistently reciprocated for reasons of convenience and political expediency.

You have the wholehearted support of this organisation in trying to redress the balance. Infected healthcare professionals are not pariahs to be cast out into the dental wilderness, but real people, and - let us not forget - they are patients themselves.

$\mathrm{K}$. Lewis

Dental Director

Dental Protection Limited

doi: 10.1038/sj.bdj.4814313

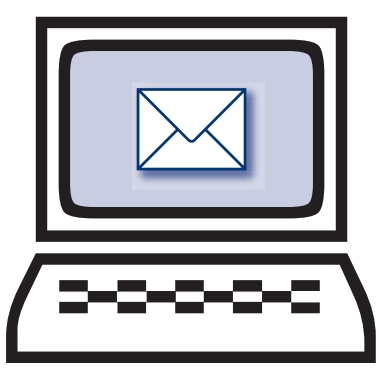

Lacking evidence base

Sir, I note with interest the opinion article Written off (BDJ 2006; 201: 497-499). The Equality and Diversity Committee (EDC) of the BDA are also deeply concerned at the institutionalised barriers facing our peers with HIV. Not only is the evidence base for the current guidance painfully lacking, but compounding the situation is that government support mechanisms for those in dentistry diagnosed as HIV positive are virtually non-existent. This greatly and unnecessarily exacerbates the stress, suffering and professional isolation of those that are or become infected. The EDC supports wholeheartedly calls for UKAP to undertake a complete revaluation of their guidance based on scientific assessment, and to ensure that they exclude potentially discriminatory factors. They may also wish to consider the situation in the light of recent (and overdue) additions to the Disability Discrimination Act which make it unlawful to discriminate against a person with HIV. The BDA has maintained a watching brief on this matter since the last DH guidelines in 2005 and continue to co-ordinate their position and response with other stakeholders.

\section{J. Husband}

Chair, BDA Equality and Diversity Committee doi: 10.1038/sj.bdj.4814315

\section{No justification}

Sir, the article by David Croser (BDJ 2006; 201: 497-499) and your accompanying editorial draw attention to the plight suffered by dentists in the United Kingdom who become HIV positive and to the shameful way they are treated by the Department of Health and Health Authorities. The risk of a patient (or other member of the dental team) being infected by an otherwise healthy HIV positive dentist is infinitesimally small, so there is no justification for invoking the 'look back procedure' or insisting that he or she can no longer practise dentistry. Members of the dental profession are encouraged to practise evidence based dentistry; it is regrettable that evidence appears to play so small a part in the drafting or amending of regulations and guidance on this and other issues. 
I am sure that the advice given to the Department of Health some 20 years ago in the wake of the case of Dr Acer (the Florida dentist) was reasonable at the time. But much has changed since then. There has been no evidence of transfer of the virus from an infected dentist to a patient and antiretroviral drugs are reducing the viral load and prolonging the lives of those who have become HIV positive.

As health professionals we know that one of the greatest problems confronting HIV positive individuals is the stigmatisation and ostracisation that can occur at a time when compassion and understanding are most required. But here in the UK we are doing just that by unnecessarily ruining practitioners' businesses and summarily terminating their careers. I am no lawyer but I also wonder if such treatment might well contravene human rights and disability discrimination legislation.

With this months World Aids Day on 1 December it is timely for the Department of Health and Health Authorities to alter their guidance and procedures to fall into line with those countries that recognise the scientific evidence and allow HIV infected practitioners to continue working provided their health status and practice arrangements are regularly monitored. If they are unwilling to do so then a well orchestrated and planned campaign is required to persuade them to do so. Our professional colleagues deserve nothing less.

J. M. G. Hunt OBE

Beaston

doi: 10.1038/sj.bdj.4814314

\section{Supernumerary molars}

Sir, supernumerary molars occur far less frequently compared to other supernumerary teeth. ${ }^{1}$ While the literature reports on fourth, fifth, sixth and seventh molars, it is extremely rare for patients to have impacted fifth molars bilaterally. ${ }^{2}$ To the best of our knowledge, the following case is the first of its kind in the literature, which describes bilateral impacted fourth and fifth molars in the maxilla and an impacted fourth molar in the mandible.

A 21-year-old female patient presented to the oral diagnosis clinic for routine dental treatment. There was occlusal and aproximal caries in the permanent molars and following clinical examination, panoramic and periapical radiographs were taken. The panoramic radiograph (Fig. 1) revealed five supernumerary molars with maxillary fourth and fifth molars bilaterally (UR9, UR10, UL9, UL10) and the mandibular fourth molar (LR9) impacted radiographically. The fourth and fifth molars were all present distal to the third molars although one fourth molar on the maxillary right quadrant was smaller in size. A general physician was consulted who confirmed that there was no associated syndrome. Root canal treatment was carried out for the right first mandibular molar while a surgical procedure was considered for the impacted supernumerary teeth and third molars.

Supernumerary molars exist bilaterally in almost a quarter of cases ${ }^{2}$ and dentists should keep this in mind when examining the oral cavity, both clinically and radiographically, when a supernumerary molar is found.

\section{K. Gündüz}

Turkey

1. Kokten G, Balcioglu H, Buyukertan M. Supernumerary fourth and fifth molars: a report of two cases. J Contemp Dent Pract 2003: 15: 4: 67-76.

2. Grimanis G A, Kyriakides A T, Spyropoulos N D. A survey on supernumerary molars. Quintessence Int 1991; 22: 989-995.

doi: 10.1038/sj.bdj.4814316

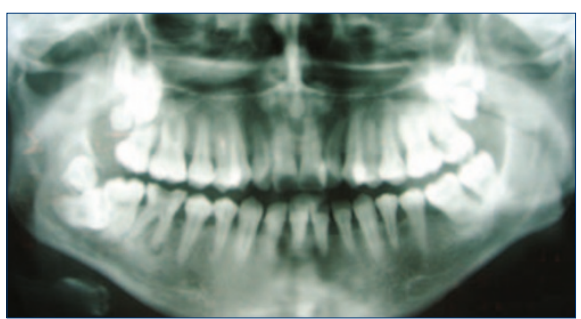

Fig. 1 The panoramic radiograph showing the impacted mandibular fourth molar

\section{Irrelevant oral health}

Sir, watching my Ghanaian 'minder' tease the last few fibres of gristle from a goat's half mandible, I ask when he last went to the dentist (Dental charity work - does it really help? BDJ 2006; 201: 413). He is bemused. Oral health for him, for his family and friends is an irrelevance.

On my annual visits to the Ghana, I am moved by the sights of beggars with no limbs (a consequence of the Rwanda Genocide) and the long hospital queues of mothers hoping they can be given just a few tablets of Malarone ${ }^{\circledast}$ for their desperately ill, malarial-fevered infants. The cost for a course of treatment is only about $€ 6$ but the average annual income is $£ 300$. On the last night of my visit, I stay in my minder's three roomed quarters with his family. There is no running water, I urinate against the side of the building and the malaria mesh is stretched, buckled and pointless. I will not patronise him with platitudes such as "urgent oral treatment affordable fluoride toothpaste - atraumatic restorative treatment' (WHO-endorsed Basic Package of Oral Care).

So why do I contribute to the existing western-style prosthodontics programme at the University of Ghana Dental School? The answer lies with the 'Difference Principle.' ${ }^{1}$ Rawls argued the promotion of differences can be just, providing the resulting inequalities improve the lot of the disenfranchised. If the leaders of disadvantaged communities/countries cannot access appropriate health care, not only will they be unable to ventilate and arrange for the creation and redistribution of resources but they will seek care outwith their country, haemorrhaging scarce foreign currency.

Any public dental care provision in a heavily indebted poor country should at best be 'discretionary' with little place for an American/Eurocentric dental health model. The present programme at the University of Ghana focuses on training dental personnel to work in synergy with other local health care workers. I complement this by teaching sophisticated dental reconstructive techniques in order to meet the need of the leaders of the country. My flights and accommodation are paid by the Ghanaian government.

I applaud those who pay for themselves in order to work with and for existing local dental care provision in poor countries.

\section{J. R. Radford}

By email

1. Rawls J. A theory of justice. Belknap, 1971.

doi: 10.1038/sj.bdj.4814317

\section{Rise of the PDP}

Sir, postgraduate dental education is going through a process of change at the moment, which is having far reaching effects on everybody involved in training and education. There is increasing importance being placed on dental professionals keeping a professional development portfolio (PDP). The purpose of the PDP is to help keep a record of key events that may take place during a professional career. The portfolio also provides evidence of the skills developed and competencies gained during postgraduate training. It demonstrates reflective thinking strategies, shows professional growth over time in diverse clinical environments and relays personal attitudes toward continuing professional development.

By keeping a record of clinical work and personal documents of achievement, graduates can build a visual representation of their past contributions that allow others to gain a deeper and clearer picture of where they have been, where they are now, and where they are going in the dental profession. Evidence of goal setting, pinnacles reached, and future career ambitions are all reflected in a consummate professional portfolio. 
It is hardcopy proof of talents you possess and provides insight into potential areas of interest. In this increasingly litigious world a professional development portfolio will also provide evidence of a dentist's level of clinical competency during medico-legal complaints.

A standardised postgraduate PDP should be developed in collaboration with all the deaneries within the United Kingdom. As competition for specialist training increases, it is imperative that dental graduates keep a PDP. Many times applicants seeking a specialist training position begin to sound and look alike. A portfolio is a way to show individuality and creativity. This portfolio can then be submitted as part of the application for specialist training. This will bring together within one folder all the necessary documentation to allow appraisal and assessment to take place and hence will provide the selection committee with more objective criteria on which to judge the candidate.

In summary, the PDP is an essential tool that every dental professional should keep. V. Gohel

By email

doi: 10.1038/sj.bdj.4814318

\section{Spurious credibility}

Sir, I notice with dismay the appearance of advertorials in recent issues of the $B D J$. For those not familiar with this concept, the advertorial is an advertisement disguised through typesetting and layout to look like the editorial content of the journal. This is at best an ethical grey area and at worst simple fraud, with magazine editorial staff responsible for plugs and advertising text from companies that they should keep at arm's length. The genre reaches its heights (perhaps depths?) in popular magazines where biased and misleading content is disguised within apparently independent articles. Advertorial has been described as information pollution. ${ }^{1,2}$

The publication of advertorial material is, surprisingly, acceptable to the FDI Code of Ethics for Dental Publications provided it is clearly marked as such and I accept that these articles have been typeset differently from the journal articles. However, the whole concept of advertorial is to gain spurious credibility for advertising material and to make it look as though the publication and its expert advisers endorse the product. Advertorials are considered not to comply fully with the editorial standards of newspapers and there should be no place for them in the $B D J$ or in any professional journal that values its credibility and independence. Will we be seeing edutainment in the $B D J$ soon? E. W. Odell London
1. Cameron G T, Ju-Pak K-H. Information pollution? Labelling and format of advertorials. Newspaper Research J 2000; 21: 65-76.

2. Ellerbach J. The advertorial as information pollution. J Information Ethics 2004; 13: 61-75.

The Editor-in-Chief responds: I thank Dr Odell for his letter. Advertorials are not new to the BDJ and are common enough elsewhere that $\mathrm{BDJ}$ readers are hardly likely to be deceived into thinking them to be editorial copy of the credible and independent type on which this journal prides itself. In any event, as Dr Odell points out, advertorials are typeset differently to other content and marked clearly at their head 'Advertorial'. It might be argued that all content of all adverts may be classed as advertorial in that it is, presumably, the opinion of the advertiser but without the 'safeguard' of the label to which Dr Odell seems to object.

Dr Odell uses the words 'spurious credibility' and 'disguise' as if all advertisers are so unsure of their products and services that he feels they have to hide behind deceitful claims. In reality, I believe that we are in general 'old enough and ugly enough' (as my Grandmother used to put it) to know what's what in terms of unlikely or exaggerated claims.

Looked at from the opposing view, our surveys inform us that many readers are appreciative of the adverts to inform them of products and services currently available. Indeed, when we recently ran an advertorial in our sister publication BDA News, a similar letter of protest (sent, not for publication) was matched 10-fold by a delighted advertiser who reported great interest as a result - some readers it seems are not so concerned nor so easily duped. doi: 10.1038/sj.bdj.4814319

\section{Incidental findings}

Sir, I would like to take this opportunity to remind my colleagues of the importance of thorough radiographic examination. Having only had brief experience of the dental services to date, following graduation in 2004, I have come across several examples of incidental findings on dental radiographs which patients have not been aware of. The following case, although seemingly trivial, reiterated to me the importance of thorough systematic radiographic review, documentation of findings and informing patients.

An 18-year-old Asian male presented following a course of orthodontic treatment to have definitive restorative management of spaces that had been opened to manage his hypodontia. As part of a thorough history-taking his previous radiographs were examined. On his dental panoramic radiographs from 1993 to 2004 (Figs 1-4), the development of a radiopacity in the left maxillary antrum was noted, which had been gradually growing in size. Final presentation showed an ovoid uniform radiopacity of approximately $2 \mathrm{~cm}$ in its greatest diameter with a well defined smooth border and no apparent effects on adjacent structures, suggesting a left sided maxillary antral polyp. The patient reported he was unaware of this finding, so it was explained to him what an antral polyp was. In addition I contacted the local maxillofacial department seeking advice as to whether a referral was required to manage this patient further. B. Qureshi

Manchester doi: 10.1038/sj.bdj.4814320

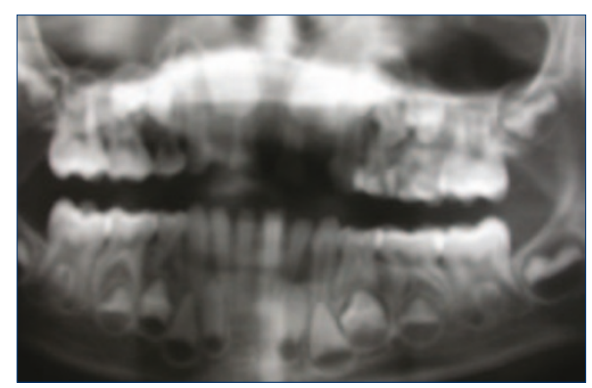

Fig. 1 November 1993

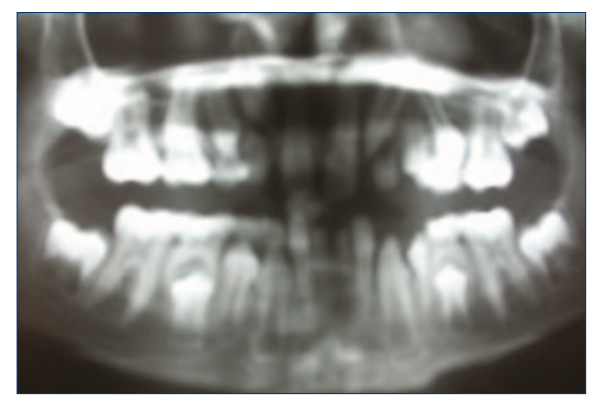

Fig. 2 October 1998

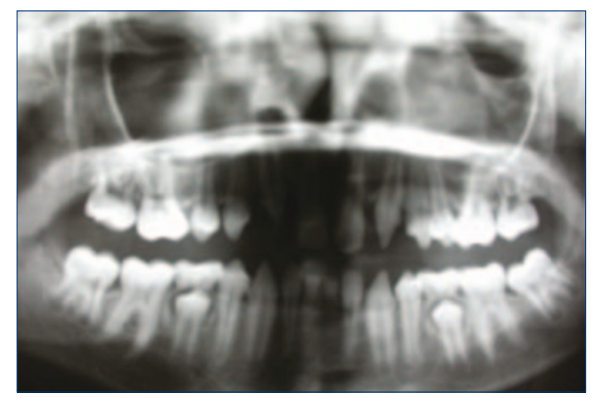

Fig. 3 February 2000

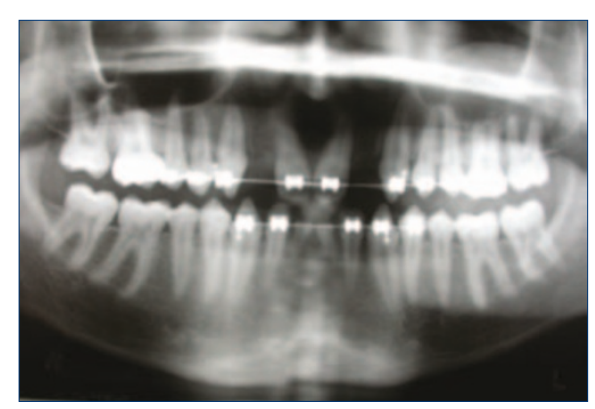

Fig. 4 May 2004 